International Journal of Engineering \& Technology, $7(4.5)(2018) 333-340$
International Journal of Engineering \& Technology
SPC
Website: www.sciencepubco.com/index.php/IJET
Research paper

\title{
A Comparison of Fatigue Life Improvement Methods for an Existing Offshore Jacket Platform Structure
}

\author{
Swethima Reghu ${ }^{1}$, Sruthy $\mathrm{S}^{2 *}$ \\ ${ }^{l}$ Post graduated student, Department of Civil Engineering, Amrita School of Engineering, Coimbatore, \\ Amrita Vishwa Vidyapeetham, India \\ ${ }^{2}$ Assistant Professor, Department of Civil Engineering, Amrita School of Engineering, Coimbatore, \\ Amrita Vishwa Vidyapeetham, India \\ *Corresponding author E-mail: s_sruthy@cb.amrita.edu
}

\begin{abstract}
Most offshore Jacket platforms are installed in shallow water, less than 300 meters for drilling and production of oil or gas. They are normally fixed to seabed and constructed as three dimensional frameworks with tubular members as structural elements. The surrounding environment around offshore platform is affected by various environmental loads that comprise of wind, waves, currents and earthquake. The major load in such structures is wave loading, repetitive in nature which causes time varying stresses that results global and or local fatigue damage on the offshore steel structure. This study includes fatigue assessment of a selected jacket structure using ANSYS software. This study concentrates mainly on the stress reduction at joints by various methods under the applied cyclic loading. The various methods considered in this study are providing: joint cans with branch stubs, grouted connections, FRP wrappings, stiffeners at the joint section. A comparison of various methods for reducing the hotspot stresses which increases fatigue life are studied and the most effective one is recommended.
\end{abstract}

Keywords: ANSYS; Fatigue; hot spot stress; Jacket platform; stress concentration factor

\section{Introduction}

The offshore exploration of oil and gases has developed rapidly over the last four decades. Since the nineteenth century, various types and sizes of offshore platforms have been constructed and installed worldwide. One of the most common offshore structures used for drilling and production is the Steel Jacket or Template platform. Steel jackets are vertical sections made of tubular steel members, and are usually piled into the seabed. Thus jacket structures consist of interconnected tubular members to form a threedimensional frame which have four to eight legs battered to achieve stability. Historical development of jacket structures from fabrication to installation processes is discussed by Chakrabarti $\mathrm{K}$ Subrata(2005) [1] in his works.

The existing structures used in the petroleum industries have been designed for a life of around 25years. The developments in the possible oil recovery have increased the demand for using the structures well beyond their design period.

Since the 1950s, the procurement of new environmental data there has been a rapid increase in the loads which these structures have to withstand. Thus there is an increased need to upgrade the structure to meet the new requirements. [2]

The various environmental loads acting on these structures include the wind, waves, currents and earthquake and the existence of load cycle or repetitive load, such as wave induced dynamic force(causing time varying stresses) leads to fatigue damage of these structures. Thus analyzing fatigue behavior is highly important in offshore structures. Fatigue occurs mainly in joints of tubular members. A.A. Khalifa et al [3] performed fatigue assessment of welded tubular joints of fixed platforms using SN curve approach. Modeling and various assumptions for the computation of jacket structure are discussed. The application of hydrodynamic forces on tubular components in accordance with the wave histogram is studied. Almar-Naess [4] discussed the important aspects of calculating fatigue lives and stresses. Studies on fatigue and their fatigue improvement methods have gained more popularity in the recent decades. Different failures and their failure modes have been investigated thoroughly. Chul-Hee JO et al and I.YaminiSreevalli et al [6] have conducted large scale experiments on tubular joints at various conditions. It was concluded that the maximum stress at the joints varied according to the variation of joint parameters.

In the hotspot stress reducing studies Baker Jardine[7] conducted fatigue test on repaired and fully internally grouted tubular welded $\mathrm{T}$ joints and the results suggested that the grouting technique may be applied to existing nodes to extend their fatigue lives by reducing the hot spot stresses around the chord/brace intersection and also the existing S-N curve approach for these grout stiffened nodes is applicable. Further in the advanced study of the grouts Thandavamoorthy TS et al [8] proposed a repair technique which has made use of Ferrocement jackets and High Performance Grout (HPG). The study was conducted on three corrosion fatigue damaged tubular joints and the joints were tested under axial brace compression loading after applying the new repair material. The joints exhibited composite action due to the excellent bond of the HPG with the tubular joints. Strength of repaired joints was predicted using an analytical model. Among the various studies conducted indeed shows competent results. 
In this study as a part of integrity study the fatigue assessment and fatigue behaviour of the selected jacket structure is carried out Further various methods for reducing the hot spot stresses which eventually increases the fatigue life are reviewed. Thus different effective and optimized methods for reducing the hot spot stresses at the welds are studied.

\section{Methodology}

The location details and structural details of the jacket platform required for modelling was collected. The selected structure is modelled in ANSYS software (Workbench 16.1). Loads acting on the structure both environmental and equipment loads acting on the structure is calculated and applied. SN curve [9] of base steel is incorporated into structure and the fatigue life is obtained. Hot spot stresses were calculated and critical area of damage was identified. Methods for strengthening the weaker sections were studied and their effectiveness was reanalysed and observed. The various improvement methods selected for this study are:

1. Joint cans with branch stubs

2. Grouted connections

3. Fiber Reinforced Polymer wrappings

4. Stiffeners

\subsection{Structural Details of Platform}

The selected jacket structure is a four legged piled fixed platform located in Eastern block of the Gulf of Suez, Egypt. The platform is installed in 33.5 meter water depth. The of the location of the structure lies in latitude $28.5^{\circ} \mathrm{N}$ and longitude $33.5^{\circ} \mathrm{E}$

Platform Configuration: The platform is four legged piled fixed type. The spacing in East direction between Row-A to Row-B is $7.62 \mathrm{~m}$ and in the North direction between Row- 1 to Row- 2 is $7.62 \mathrm{~m}$; at working point elevation of (+) $5.182 \mathrm{~m}$. The production deck at topside is of $18 \mathrm{~m} \times 22 \mathrm{~m}$ ) as shown in fig 1 .

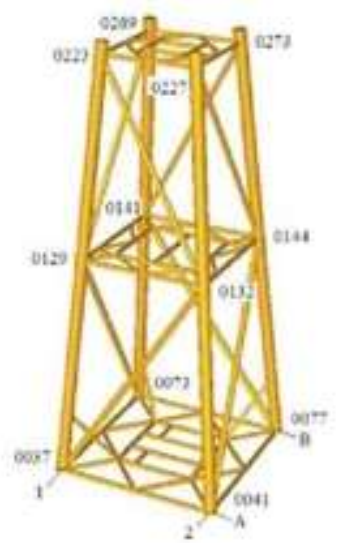

Figure 1: Structural details of the platform (Source: A.A. Khalifa et al (2014))

The fixed jacket consists of three horizontal bracing diaphragms at elevations (+) $3.048 \mathrm{~m},(-) 13.176 \mathrm{~m}$ and (-) $33.00 \mathrm{~m}$, respectively. The bottom bracing level is at elevation (-) $33.00 \mathrm{~m}$, where the piles are fixed at the mud-line. The jacket batter is 1:12 (horizontal: vertical) for all the faces. The jacket legs are built of tubular sections of 40 inch diameter, supported on the piles of tubular sections 36 inch diameter. The bracing system is K-type with different tubular sizing varying from 18 to 22 inches diameter.

\subsection{Wave Data and Hydrodynamic Forces}

Table 1 below gives wave parameters for one year return period. [10]
Table 1: Wave Parameters (Source: A.A. Khalifa et al (2014))

\begin{tabular}{|l|l|}
\hline WAVE INPUT PARAMETERS \\
\hline Wave height $(\mathrm{H})$ & $2.15 \mathrm{~m}$ \\
\hline Time period(T) & $5.08 \mathrm{~seconds}$ \\
\hline Wave depth $(\mathrm{d})$ & $33.5 \mathrm{~m}$ \\
\hline Free Board & $1 \mathrm{~m}$ \\
\hline Wave Number(K) & $0.156 \mathrm{~m}$ \\
\hline Wave Length $(\mathrm{L})$ & $40.9 \mathrm{~m}$ \\
\hline Frequency $(w)$ & $1.236 \mathrm{rad}$ \\
\hline Sea Water Density $(\rho)$ & $1030 \mathrm{~kg} / \mathrm{m}^{3}$ \\
\hline Drag coefficient Cd & 0.5 \\
\hline Inertia coefficient Cm & 2 \\
\hline
\end{tabular}

The load characteristics for the offshore structure are considered with reference to API RP2A Guidelines [11]. The force exerted on a fixed vertical cylindrical pile by surface waves was calculated using Morison equation, under the restriction that the diameter of the pile is small in comparison with the length of the wave encountered. Morison equation [12] is expressed as:

$\mathrm{F}=1 / 2 \rho C_{D} A U|U|+\rho C_{M} A V a$

$\mathrm{C}_{\mathrm{D}}$ is drag coefficient, $\rho$ is density of water, $\mathrm{A}$ is the projected area normal to the cylinder axis per unit length, $\mathrm{V}$ is the displaced volume of the cylinder per unit length, $U$ is the component of the velocity vector of the water normal to the axis of the member, $|\mathrm{U}|$ is the absolute value of $\mathrm{U}, \mathrm{C}_{\mathrm{M}}$ is the inertia coefficient, $\mathrm{a}$ is the component of local acceleration.

\section{Modeling of Jacket in ANSYS}

The selected jacket structure was modeled in ANSYS software .The primary elements modeled has six degrees of freedom at each node translations in and rotations about the nodal $\mathrm{x}, \mathrm{y}$, and $\mathrm{z}$ axes. The structure under water was divided in to 33 members for the application of varying load throughout the depth as in fig 2 .

For the analysis of a 4 legged Jacket structure minimum 8 directions of the wave loads shall be considered.The structure is analysed for various combination of these loads acting in eight different directions spanning from zero degree to 180 degree. While subjecting the platform to the loading conditions wave and current flow directions of $\pm 0^{\circ}, \pm 45^{\circ}, \pm 90^{\circ}, \pm 135^{\circ}$ and $\pm 180^{\circ}$ are intended as shown in fig 3 different load cases have been considered for analysis of this platform [13].

For operating conditions of platform, with progressive angle of the wave, and sea current attack, angle from zero to 180 , platform displacements is reduced i.e., the angle of zero degrees shows the maximum displacement and 135 degrees exhibits the minimum displacement in the $\mathrm{X}$ direction. This trend is observed for 100 year wave also. From the analysis carried out in ANSYS the structure shows maximum displacement for the load combination of DL+LL+ wave $_{0 \text { year }}+$ angle $0^{0}$.

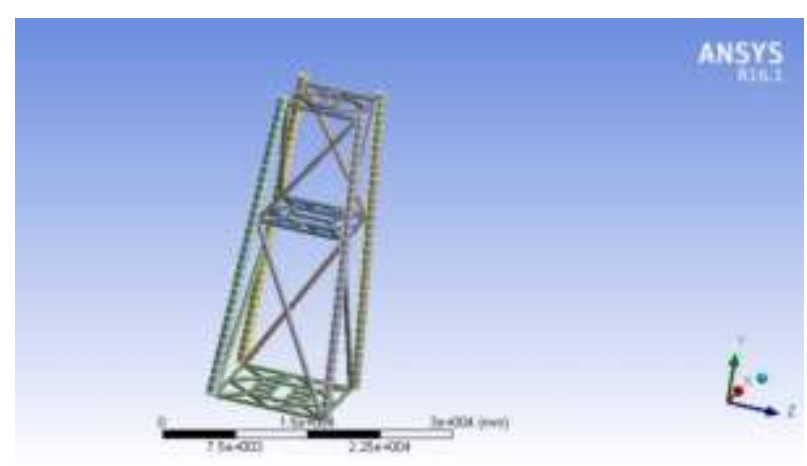

Figure 2: Structure modeled in ANSYS 


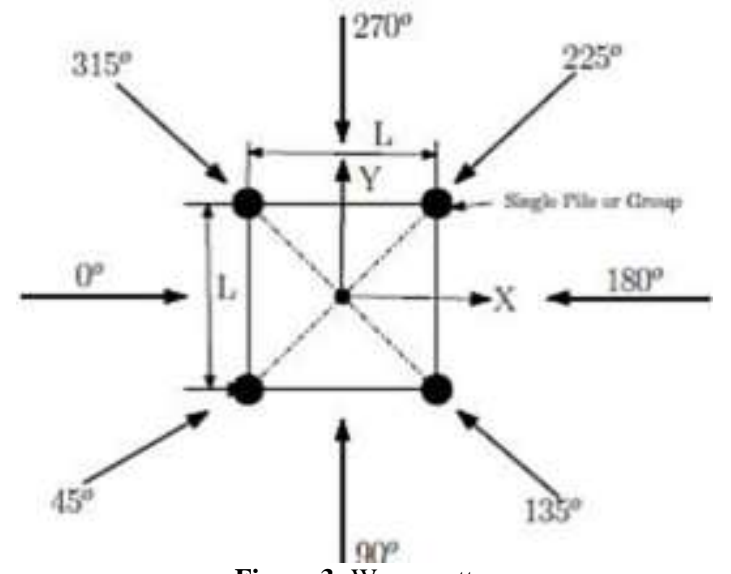

Figure 3: Wave scatter

\subsection{Fatigue Parameters}

\subsubsection{S N Curve and Stress Concentration Factors}

The relationship between the number of load cycles $\mathrm{N}$ to failure and the nominal stress ranges $\mathrm{S}$ applied to a given sample is given by $\mathrm{SN}$ curve which are experimentally determined. The SN curve in seawater with cathodic protection for tubular joints as per DNV code (cl.2.4.5 Table 2-2, fig2-9) [9] for the structural steel provided was inputted. The stress variation throughout the length of structure was obtained.

The SCF can be obtained from the DNV code (Table 2-2) and these vary for different parameters geometry, load distribution etc. Thus incorporating the above conditions and the welds provided the appropriate value for SCF to the corresponding SN curve is selected as 1.61. The tubular joint with weld made from single side without a backing strip provided that full penetration is achieved is applied [14]. It is standard practice to involve parametric equations for calculating SCFs to derive the hot spot stress of joint.

$\mathrm{SCF}=(\sigma \neg$ hotspot $) /(\sigma \neg$ nominal $)$

In fatigue assessment, the welded regions particularly the toes of both the chord and the brace sides are located as the hot spot zone.

\subsubsection{Fatigue Life}

Under hot spot stress method, using S-N curves cumulative damage is calculated using ANSYS. The nominal stresses and their variations throughout the depth for the critical load combination are calculated and maximum value stresses were obtained at the length from $12 \mathrm{~m}$ to $20 \mathrm{~m}$ and further as the depth increased there was a decrease in the stress values.

ANSYS gives the life at different points of the structure. The large life observed in the entire structure subjected to the load combination is 100years at the bracing bays at upper and lower end of the structure and least life of structure is resulted as 0.14098 years at the joints in the mid bay for one year wave conditions as in Fig 4. Fatigue life for the load combination 7 exhibits maximum life of the entire structure as $100 \mathrm{yrs}$ and the least life of structure are resulted as 0.55099 years as in Fig 5. This least life is displayed by the tubular joints at the mid bay which at a depth of $13.176 \mathrm{~m}$ from the surface elevation.

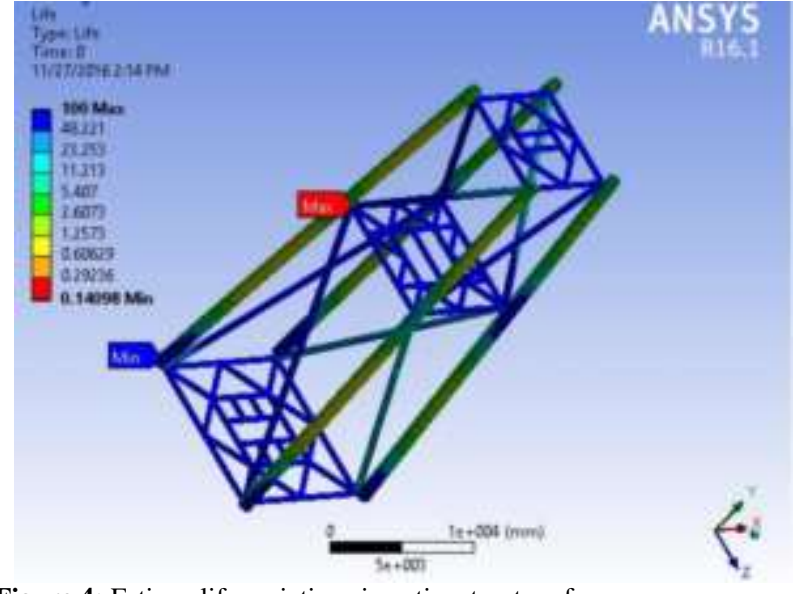

Figure 4: Fatigue life variations in entire structure for one year wave

From the fatigue life evaluation of the structure for all the combinations of loads depicts that the stress concentration is maximum at the tubular joints. For different combination of load shows different values of stress ranges and minimum fatigue life is observed at the tubular joints. Thus it is concluded that the most sensitive regions in the structure are the tubular joints. Thus for improving the fatigue life and reducing the stress concentrations at this critical sections various methods are to be studied.

\section{Modeling of Joint}

Considering the total length of the pile structure the critical section occurs at the mid bay at a height $13.176 \mathrm{~m}$ from the free surface elevation. Thus the joint alone is modeled in ANSYS i.e., single pile with the critical section is modeled as shown in Figure 5 for the extended study on the stress reduction methods.

Subjecting the joint for all the loads and analyzing, it was observed that the higher values of stresses were displayed at the intersecting region of chords and braces or at the saddle. Thus necessity for providing improvement to reduce large stresses is felt at the joint.

\subsection{SCF for Joint}

The SCF for the joint is calculated using KUANG'S formula [15]. The aim of this stress analysis is to calculate the stress at the weld toe (hot spot). The nominal stress variation for the calculated SCF was found and it displayed higher concentration at the joint regions as depicted by the entire platform. The equivalent stresses for the critical section is shown in Figure 6 for the given loading conditions.

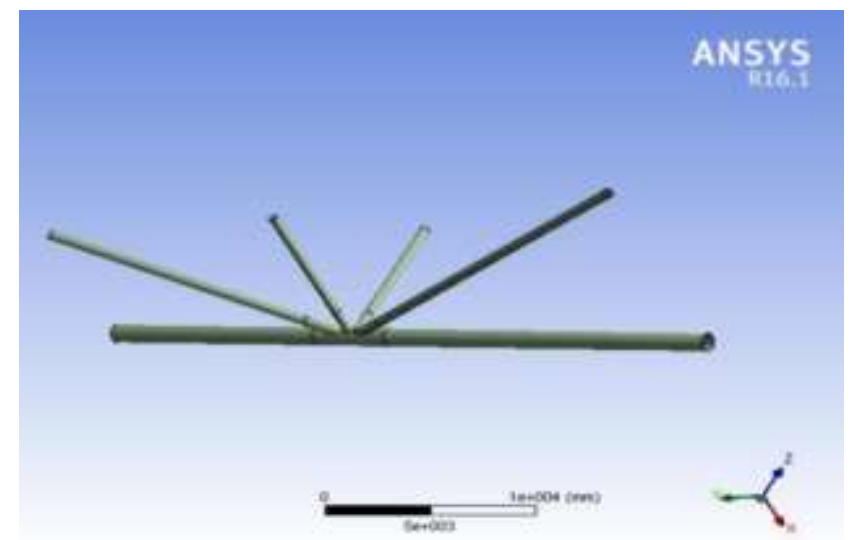

Figure 5: Joint model to ANSYS 


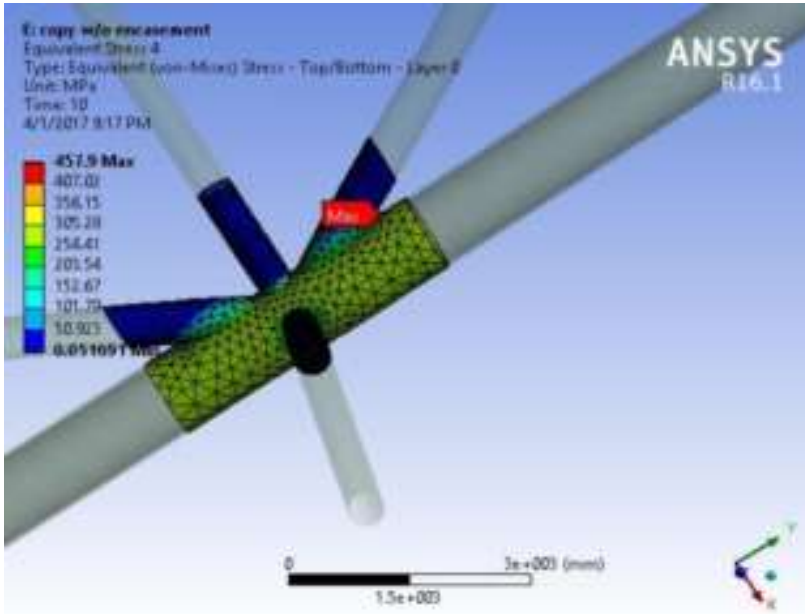

Figure 6: Equivalent stress for joint model

\section{Improvement Methods}

In the recent years the repairs of underwater structures have increased dramatically. The grouted and mechanical repair systems are of higher dominance considering the cost effectiveness and the availability of test data describing their performance. Therefore study of recent techniques and materials provides more optimized and effective solution.

\subsection{Improvement by Using Different Materials at Joints}

\subsubsection{High Performance Grout}

HPG is formed when required proportion of fly ash and sand were measured and mixed well in dry condition, then resin and hardener were mixed and added with fly ash-sand mixture to get a flowable mixture devoid of air bubbles. Properties of HPG are shown in table 2 .

Table 2: Properties of high performance grout

\begin{tabular}{|l|l|}
\hline Properties & Value \\
\hline Compressive strength $(\mathrm{MPa})$ & $70-100$ \\
\hline Flexural Tensile Strength $(\mathrm{MPa})$ & $45-60$ \\
\hline Bond strength $(\mathrm{MPa})$ & 17 \\
\hline Elastic modulus $(\mathrm{MPa})$ & $1.286 \times 10^{4}$ \\
\hline
\end{tabular}

\subsubsection{Epoxy grout}

Epoxy Grout is a 2-part $100 \%$ solvent less epoxy resin with graded fillers, which can be used as is or with additional fillers to create a range of application consistencies. Epoxy Grout is tough, durable, viscous, flowable and pourable.

Table 3: Properties of epoxy grout

\begin{tabular}{|l|l|}
\multicolumn{2}{|c|}{ Table 3: Properties of epoxy grout } \\
\hline PROPERTIES & VALUES \\
\hline Tensile strength & $30 \mathrm{MPa}$ \\
\hline Flexural strength & $25 \mathrm{MPa}$ \\
\hline Modulus of elasticity & $4.5 \times 10^{3} \mathrm{MPa}$ \\
\hline Tensile bond strength & $10 \mathrm{MPa}$ \\
\hline
\end{tabular}

\subsubsection{Fiber Reinforced Polymer}

FRP repair works by reducing the stress range experienced in the metal substrate, this method is effective before and after crack initiation, as long as the bond between the FRP and the underlying metal is maintained. The commonly used types of FRP materials i.e., CFRP and GFRP are used for the repair at joints. Properties of these materials are enlisted below:
Table 4: Properties of GFRP

\begin{tabular}{|l|l|l|}
\hline PROPERTY & LONGITUDINAL & TRANSVERSE \\
\hline $\begin{array}{l}\text { Maximum Tensile } \\
\text { strength (MPa) }\end{array}$ & $3.5 \times 10^{6}$ & 42000 \\
\hline $\begin{array}{l}\text { Modulus of elasticity } \\
(\mathrm{MPa})\end{array}$ & 76000 & 0.22 \\
\hline Poisson's ratio & 0.264 & 30912 \\
\hline Shear Modulus(MPa) & 59280 & \\
\hline
\end{tabular}

Table 5: Properties of CFRP

\begin{tabular}{|l|c|c|}
\hline PROPERTY & LONGITUDINAL & $\begin{array}{c}\text { TRANS- } \\
\text { VERSE }\end{array}$ \\
\hline $\begin{array}{l}\text { Maximum Tensile strength } \\
\left(\mathrm{KN} / \mathrm{m}^{2}\right)\end{array}$ & $3.5 \times 10^{6}$ & \\
\hline $\begin{array}{l}\text { Modulus of elasticity } \\
\left(\mathrm{KN} / \mathrm{m}^{2}\right)\end{array}$ & 76000 & $1.179 \times 10^{7}$ \\
\hline Poisson's ratio & 0.264 & 0.30 \\
\hline Shear Modlus $\left(\mathrm{KN} / \mathrm{m}^{2}\right)$ & 59280 & $6.88 \times 10^{6}$ \\
\hline
\end{tabular}

\subsection{Joint cans With Brace Stubs}

The joint is required to be resized for decreasing the larger value of hot spot stresses obtained after the analysis. Increasing the chord thickness (joint can) and branch diameter (branch stub) is provided at the area of intersection of the joint [20]. This resizing of joint is provided at a distance of almost half the diameter of the tubular member in both directions of the joints. A model which extended as an encasement to throughout the intersection connecting the chord and the braces was created for the analysis in ANSYS.

\subsubsection{Increased Thickness}

The thickness of the joint can and branch stubs is increased by different ranges and optimum thickness which does not cause structural instability is observed. The stress reduction at the critical area helps to strengthen the joint and increase fatigue life. The results show that there is $20.35 \%$ reduction in the equivalent stress

\begin{tabular}{|c|c|c|}
\hline $\begin{array}{l}\text { Thickness } \\
(\mathrm{mm})\end{array}$ & Diameter ratio $(\beta)$ & $\begin{array}{l}\text { Equivalent stress } \\
\mathrm{MPa}\end{array}$ \\
\hline 10 & 0.554386 & 383.22 \\
\hline 20 & 0.562906 & 364.69 \\
\hline 25 & 0.564986 & 369.74 \\
\hline 30 & 0.567045 & 373.45 \\
\hline 40 & 0.571107 & 380.79 \\
\hline 50 & 0.575093 & 384.91 \\
\hline 75 & 0.584741 & 390.87 \\
\hline
\end{tabular}

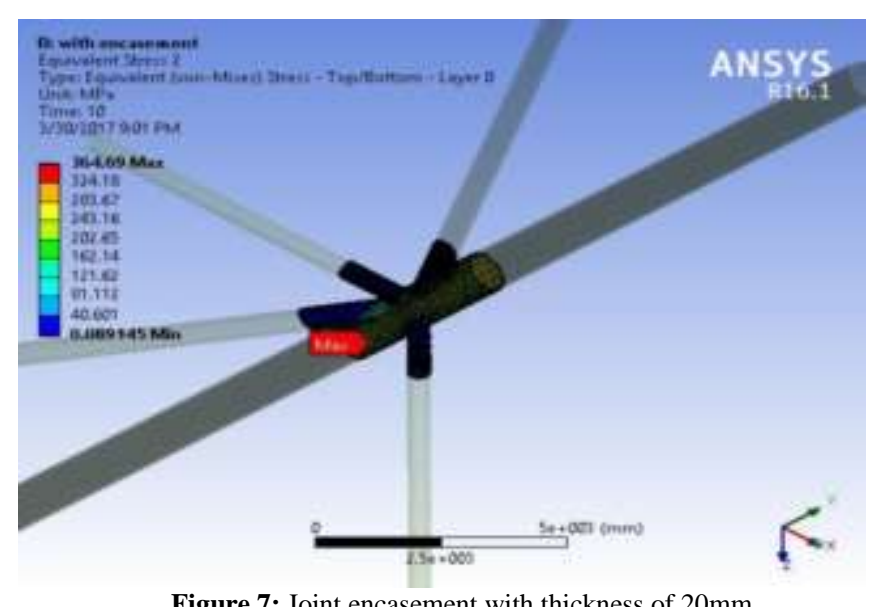

Figure 7: Joint encasement with thickness of $20 \mathrm{~mm}$

\subsubsection{Increase Thickness at Joint Can Region}

The analysis was carried out such that the increase in thickness was only provided at the chord (joint can). In ANSYS a can of circular cross section was modelled around the chord and incre- 
ments were provided. Equivalent stress reduction of $28.34 \%$ was observed as shown in figure 8 .

Table 7: stress variation in thickness in chord

\begin{tabular}{|c|c|c|}
\hline Thickness & $\beta$ & Stress \\
\hline 5 & 0.547307 & 376.86 \\
\hline 10 & 0.544639 & 353.72 \\
\hline 20 & 0.534226 & 329.11 \\
\hline 25 & 0.531684 & 329.89 \\
\hline 30 & 0.529167 & 328.13 \\
\hline 40 & 0.524203 & 327.91 \\
\hline 50 & 0.519331 & 327.82 \\
\hline 75 & 0.507539 & 327.75 \\
\hline
\end{tabular}

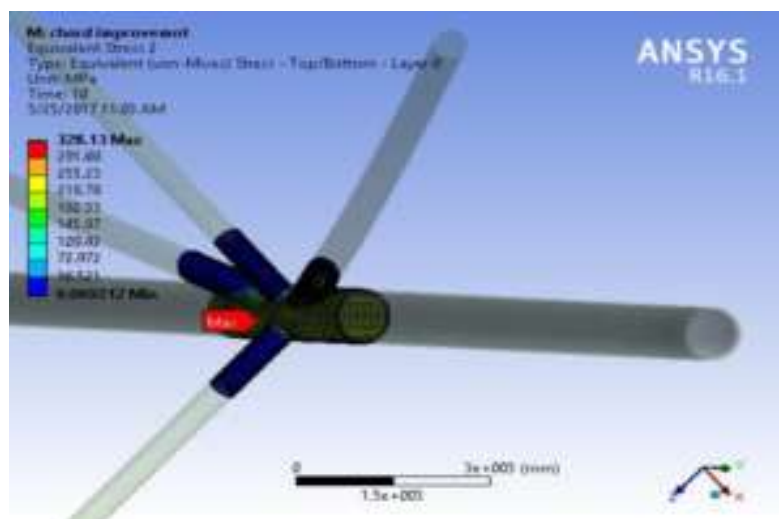

Figure 8: Stress reductions at joint can

\subsection{Grouted Connection}

Considering the critical section of joint in grouted connections the annulus between the two concentric tubular sections they are injected with cementatious material of specific adhesive properties. The outer tubular can is considered continuous in the circumferential direction. The encasement provided around the joint with the annular space between the joint can and primary structural member is filled with the different grout materials and analysed for the stress behaviour. For the optimized thickness of joint can i.e., $20 \mathrm{~mm}$ that was observed from the above result is kept constant. [16]

\subsubsection{High Performance grout}

From the analysis conducted the most efficient thickness of the grout provided is predicted as $2 \mathrm{~mm}$.HPG was provided with a thickness of $2 \mathrm{~mm}$ and the results show that there is $21.09 \%$ reduction in the equivalent stress.

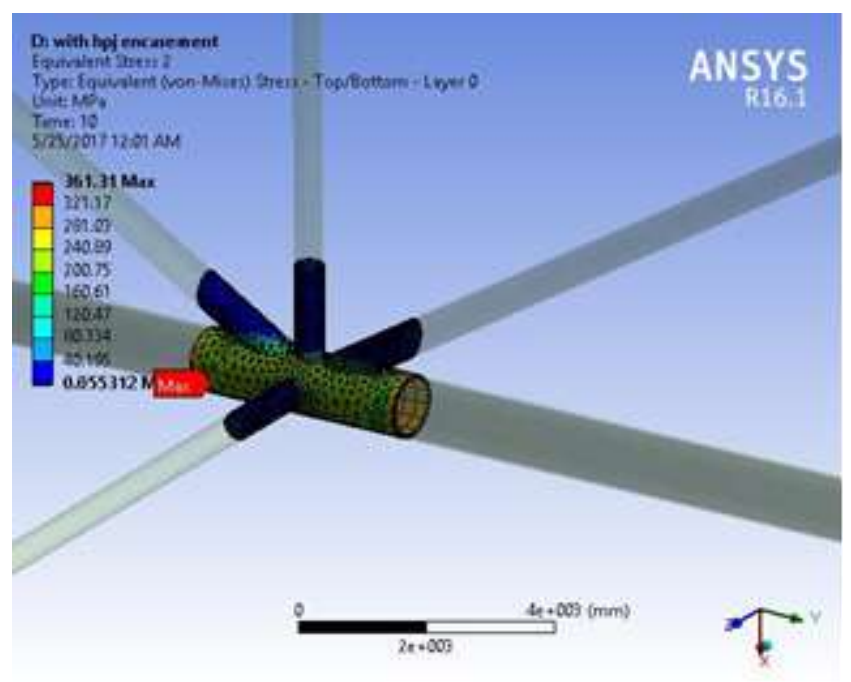

Figure 9: $\mathrm{HPG}$ with $2 \mathrm{~mm}$ thickness in the encasement

\subsubsection{HPG at Joint Can Region}

Only joint can is injected with HPG and the variation is observed. Results show that there is $27.58 \%$ reduction in the equivalent stress for $0.5 \mathrm{~mm}$ thick HPG.

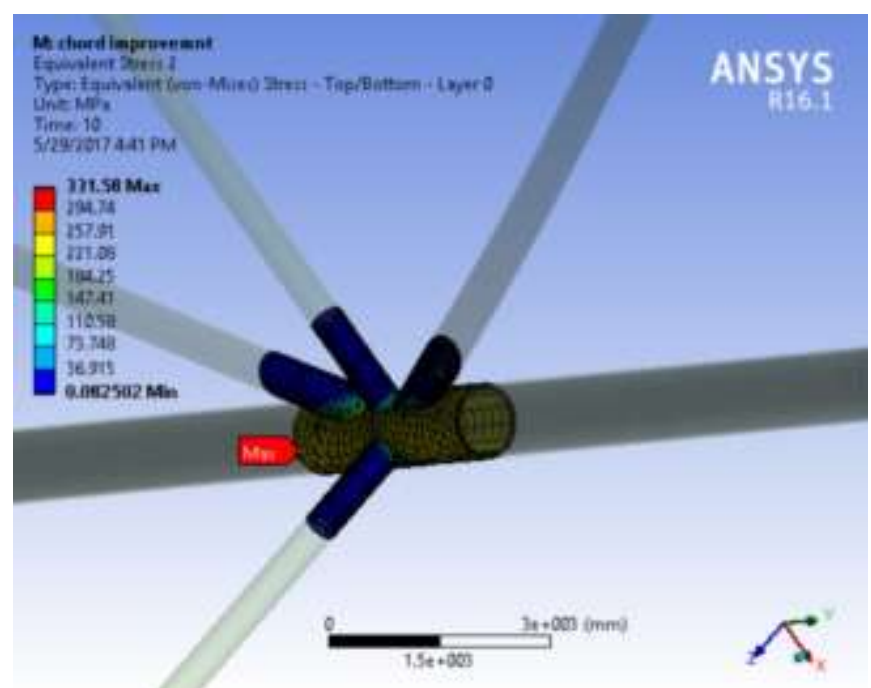

Figure 10: HPG provided in joint can

\subsubsection{Epoxy grout}

It is commonly used by industries in various sectors. In the case of providing epoxy grout it is observed that equivalent stress has reduced by $21.37 \%$ and the optimum thickness which provided maximum stress reduction for $20 \mathrm{~mm}$ thick joint can is $2 \mathrm{~mm}$. Thus grouting materials of which resembles the properties of this epoxy grout can be provided at an optimum thickness of $2 \mathrm{~mm}$.

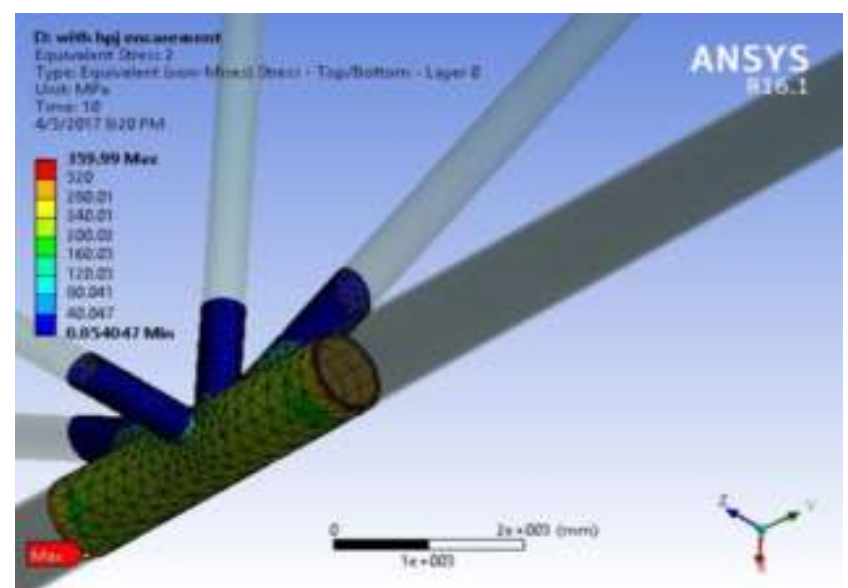

Figure 11: Epoxy grout with 2mm thickness at encasement

\subsubsection{Epoxy Grout at Joint Can Region}

Providing joint can region with $0.5 \mathrm{~mm}$ thick grout has reduced the equivalent stresses by $37.83 \%$ as shown in figure 12 .

\subsection{Fibre Reinforced Polymer}

\subsubsection{Glass Fibre Reinforced Polymer}

GFRP consists of thermosetting resins and glass fiber[17]. The GFRP is wrapped in unidirectional across the joint can region. The effect of varying thickness and angle of wrappings are analysed. Here, an epoxy primer is provided to prevent initial debonding of the material.

Minimum of 2 to 3 plies are provided with a thickness of $1 \mathrm{~mm}$, $2 \mathrm{~mm}$ and $4 \mathrm{~mm}$. The analysis showed a result of equivalent stress 
reduction of $5.34 \%$.Differences in the layout of the plies and wrapping angles were analysed and only slight variations for the stress changes were observed. As the thickness of the wrapping is increased there is only an unsubstantial reduction in the stress values (Figure 13).

\subsubsection{GFRP Wrapping at Joint Can Region}

The method of wrapping and laying up the GFRP remain same as in the above mentioned procedure. There is $9.96 \%$ of stress reduction shown for $2 \mathrm{~mm}$ thick wrapping as shown in figure 14 and further increasing the thickness by $10 \mathrm{~mm}$ the stress reduction is resulted as $10.8 \%$.

\subsubsection{Carbon Fiber Reinforced Polymer}

It is an extremely strong and light fiber-reinforced plastic which contains carbon fibers and are commonly used wherever high strength-to-weight ratio and rigidity are required. Analysis is carried out in the same way as that of GFRP. The result shows that there is some decrease in the hotspot stress at points where CFRP is applied and equivalent stress decreased by $5.34 \%$ as shown in figure 15 .
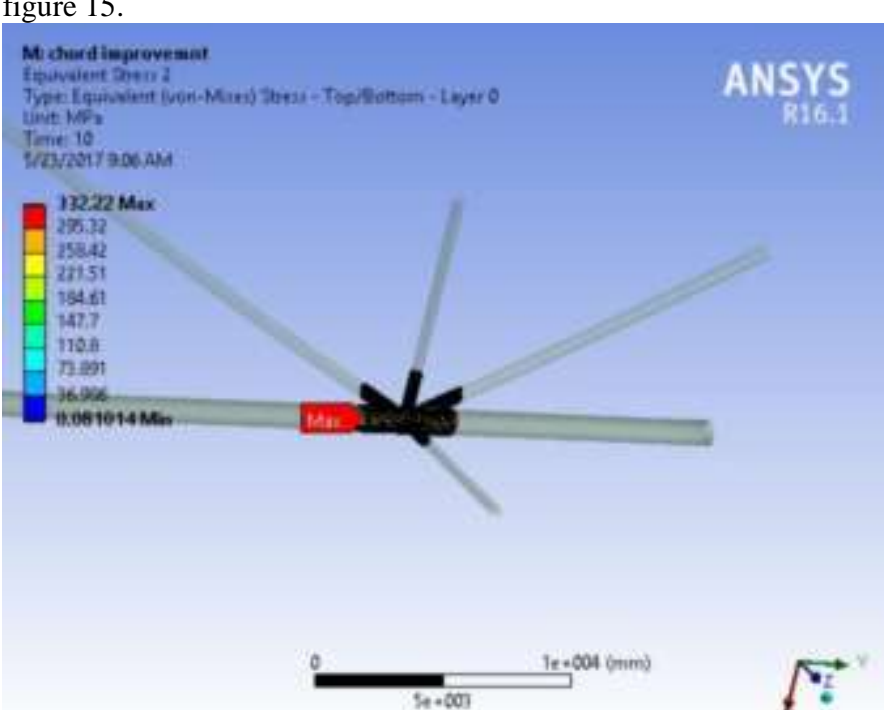

Figure 12: Epoxy grout at joint can region $0.5 \mathrm{~mm}$

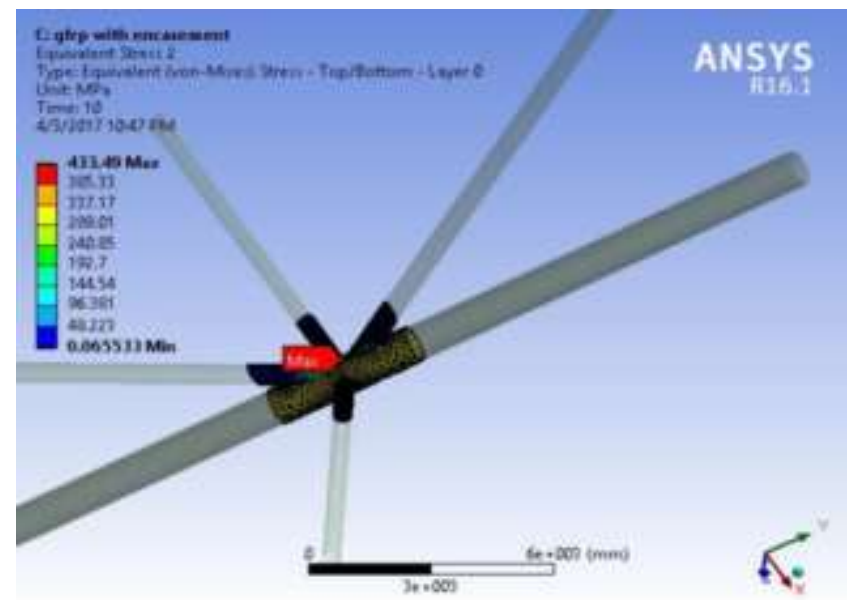

Figure 13: GFRP with 2mm thickness at encasement

\subsubsection{CFRP Wrapping Provided at Joint Can Region}

The stress reduction is shown in the region and equivalent stress has reduced by $10.133 \%$ when CFRP wrapping is provided at a thickness of $2 \mathrm{~mm}$ as shown in figure 16 and $10.25 \%$ reduction for $10 \mathrm{~mm}$ thick wrapping.

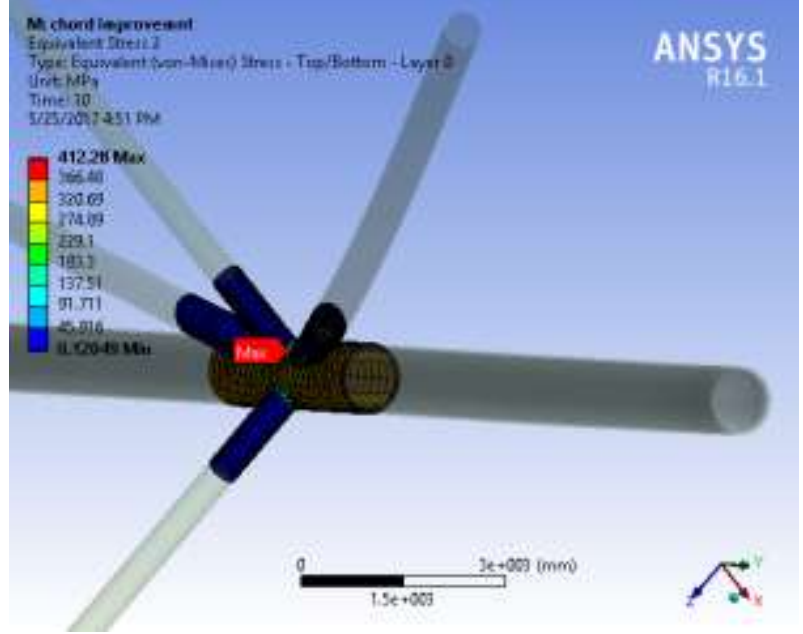

Figure 14: GFRP 2mm thick at joint can

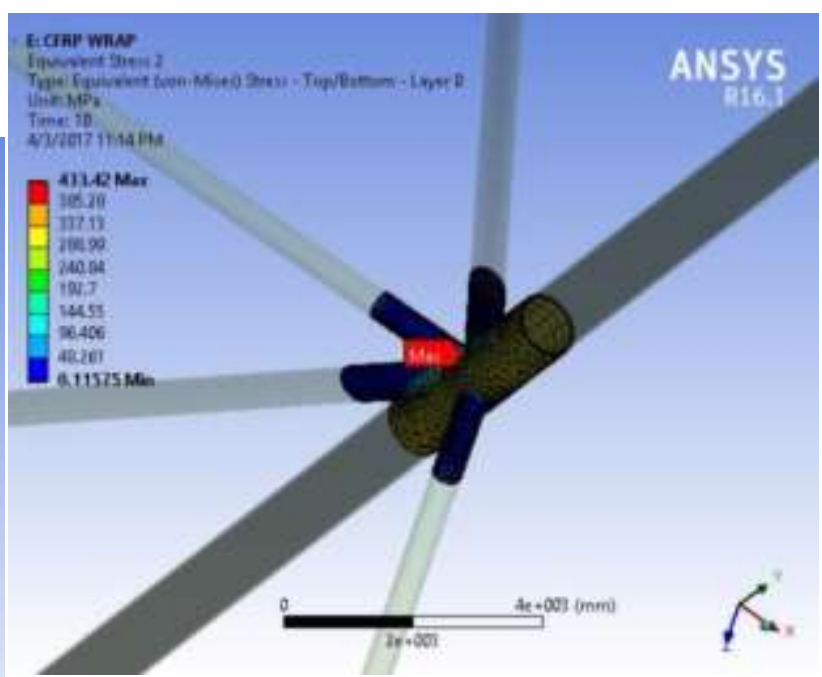

Figure 15: CFRP with $2 \mathrm{~mm}$ thickness at encasement

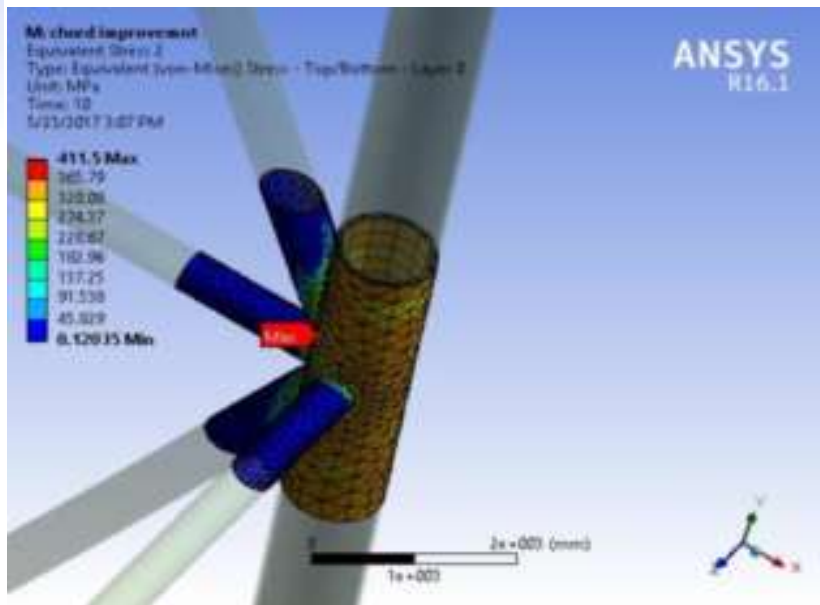

Figure 16: CFRP with $2 \mathrm{~mm}$ thickness at joint can region

Stress variation of the critical joint when provided with the various improvement methods in varying thicknesses are provided and analyzed are depicted graphically in the following figures 17.
(a) Epoxy grout
(b) High performance grout
(c) Increasing thickness
(d) CFRP
(e) GFRP 


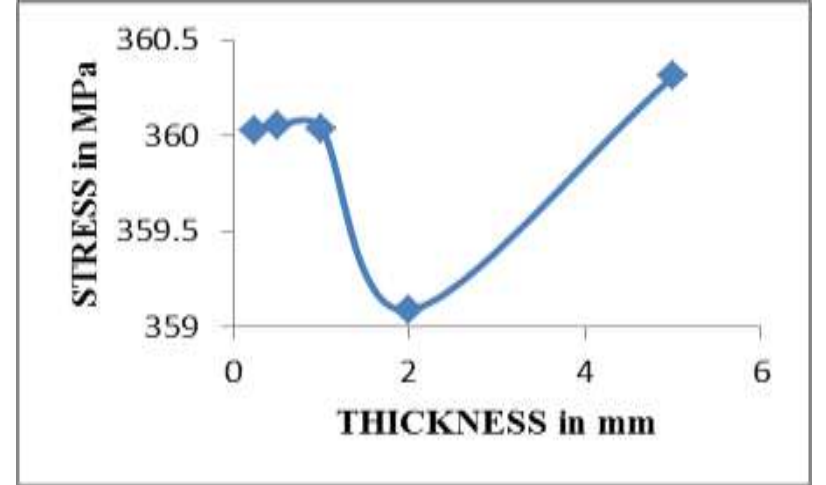

Figure 17 (a)

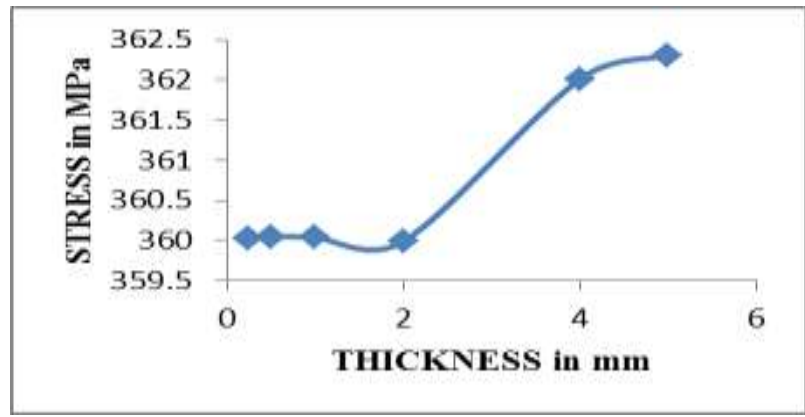

Figure 17 (b)

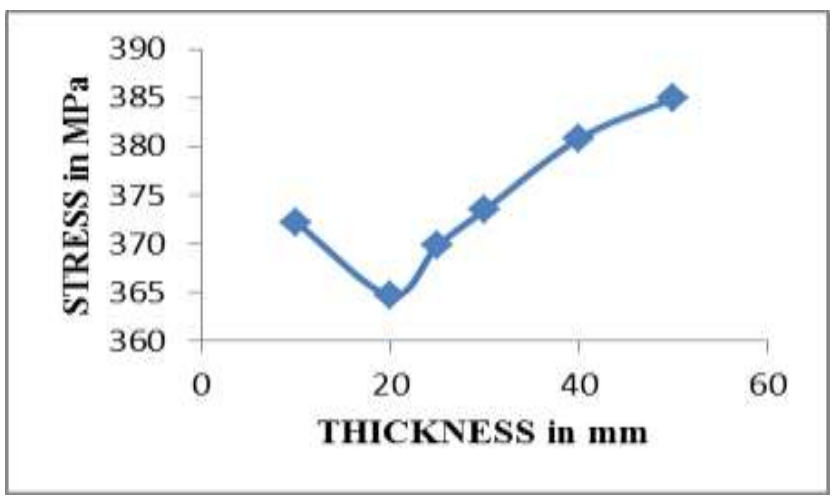

Figure 17 (c)

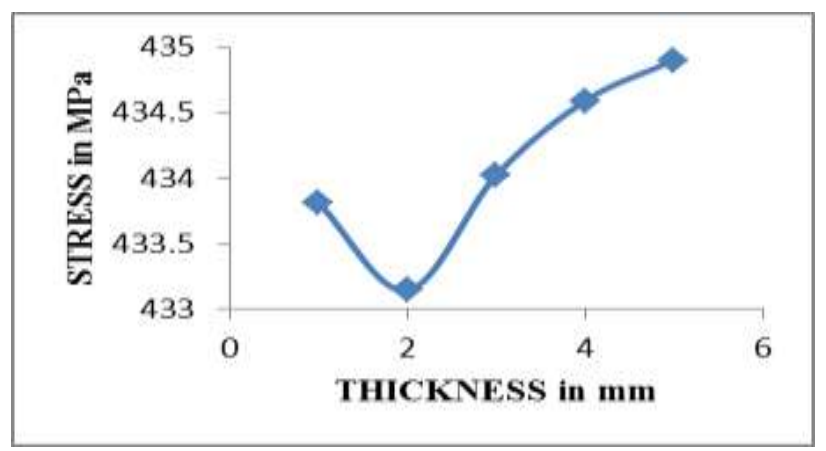

Figure 17 (d)

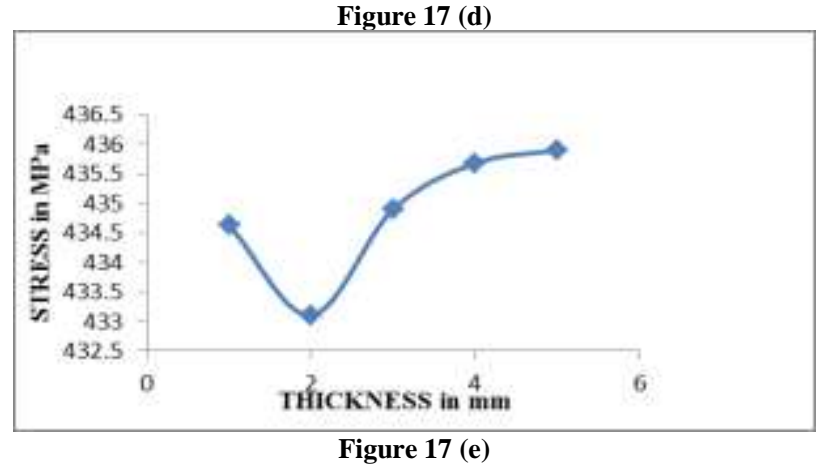

\subsection{Stiffeners}

A stiffener is adhesively attached to a portion of a surface of the steel jacket by a stiffener adhesive that is in physically contact with a portion of a first surface of the stiffener and with the portion of the surface of the jacket [19]. Large displacements and stress concentrations would also be reduced by having one or multiply stiffeners. Providing multiple stiffeners increases the stiffness of the structure as a whole with higher stability. Stress reduction after providing stiffeners is $5.12 \%$.

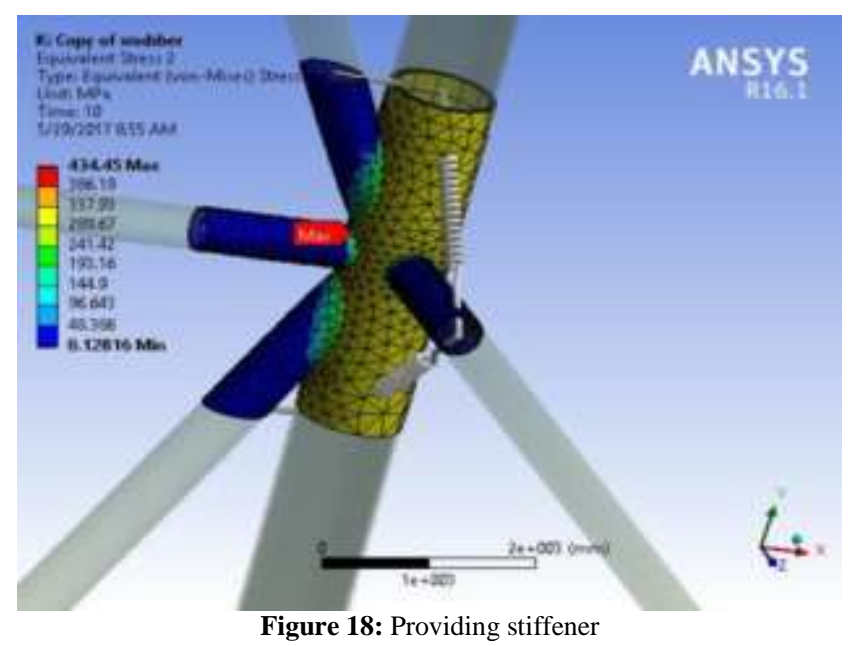

\section{Results and Discussions}

The percentage of stress reduction by using different improvement methods are tabulated in table 8 .

Table8: Percentage of Stress Reduction

\begin{tabular}{|c|c|c|}
\multicolumn{2}{|c}{ Table8: Percentage of Stress Reduction } \\
\hline Methods & Stress reduction at encasement & $\begin{array}{c}\text { Stress reduction } \\
\text { at joint region }\end{array}$ \\
\hline Joint can & $20.30 \%$ & $28.34 \%$ \\
\hline Hpg & $21.05 \%$. & $27.58 \%$ \\
\hline Epoxy grout & $21.37 \%$. & $37.83 \%$ \\
\hline Gfrp & $5.34 \%$. & $9.96 \%$ \\
\hline Cfrp & $5.34 \%$. & $10.13 \%$ \\
\hline Stiffener & $5.12 \%$ & $5.12 \%$ \\
\hline
\end{tabular}

Figure 5 and 6 shows that the hotspot stresses is maximum at the joints where number of brace elements intersects. The minimum fatigue life was observed at the mid bay at $13.176 \mathrm{~m}$. At joints present at greater depths the remaining fatigue life was higher and joints remained safe.

In $\mathrm{FE}$ analyses performed on joints to investigate the effect of improvement and their stresses, the diameter ratio $(\beta)$ was found to have the dominance on the reinforcing scheme. For composite layups, the strength enhancement was inversely proportional to the $\beta$ ratio. In other words, as the $\beta$ ratio traced to unity, the effectiveness of the improvement strategy reduced.

In the comparison of the improvement study studies carried out in the region of chord and in the encasement of joint cans and branch stubs, the stress reduction was effective when the repairs were provided in the chords. Therefore implementing these repairs in this referred area of smaller cross section in all the four joints in the existing structure would decrease the hotspot stresses and thus increases the fatigue life.

Providing grouted connections with epoxy grout considerably reduces the stress concentration. Results exhibit that while providing grouted connections the hot spot is shifted from the weld intersections to the interface between grouted can and the chord. Thus this can be suggested as an effective solution for hot spot stress 
reduction and the rehabilitation of the joints in an existing structure.

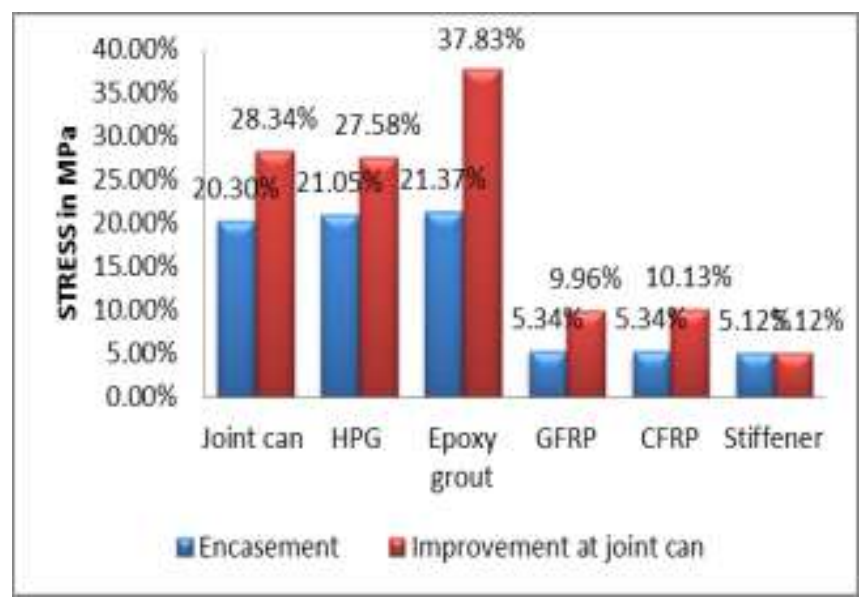

Figure 19: Comparison of the improvement methods

Scrutinizing each of these methods and analyzing their cost effectiveness, availability and ease with which the proposed methods can be implemented, injection of epoxy grout and increasing the joint can thickness are two convenient procedures. The increment in thickness can be considered in the initial stage of design, thus avoiding stress concentration.

\section{Acknowledgement}

This research did not receive any specific grant from funding agencies in the public, commercial, or not-for-profit sectors

\section{References}

[1] CHAKRABARTI, SUBRATA K. 2005. HANDBOOK OF OFFSHORE ENGINEERING .Illinois, USA : Elsevier, 2005.

[2] R G Harwood , E P Shuttleworth "Grouted and mechanical strengthening and repair of tubular steel offshore structure",1988 Techword Services publishing, London.

[3] A.A. Khalifa, S.Y. AboulHaggag and M.N. Fayed.Fatigue Assessment Analysis of Offshore Structures with Application to an Existing Platform in Suez Gulf, Egypt, World Applied Sciences Journal 30 (8): 1000-1019, 2014

[4] Almar-Næss, A., (1985), Fatigue Handbook - Offshore Steel Structures

[5] Seyyed Mahmood Ghassemi Zadeh, Reza Shojayee Baghdar,Seyyed Mohammad Saleh Vaziri Kang Olia. Finite Element Numerical Method for Nonlinear Interaction Response Analysis of Offshore Jacket Affected by Environment Marine Forces Machining Science and Technology, Journal of Marine Science, 2015, 5, 422-442.

[6] M Aswindas, S.V Venugopal., I. Yamini Sreevalli, A parametric study on efficiency of tubular joint cans in offshore structures, International Journal of Mechanical And Production Engineering, ISSN: $2320-2092$

[7] Baker Jardine."Fatigue life enhancement of tubular joints by grout injection."Health and Safety Executive - Offshore Technology Report

[8] T S Thandavamoorthy1,A R Santhakumar A G Madhava Rao "Repairing Of Tubular Joints Damaged Under Cyclic Loadings: An Innovative Technique",12th WCEE 30 Jan-4th Sept 2000 Auckland, New Zealand

[9] DNV RP-C203, DNV Recommended Practice, Fatigue Design of Offshore Steel Structures. Høvik, Norge: DetNorskVeritas, October 2012.

[10] FUGRO Global Environmental and Ocean Sciences, Gulf of Suez Met Ocean Criteria, July 2009.

[11] API RP 2A-WSD, API Recommended Practice for planning, designing and constructing fixed offshore platforms - working stress design. Washington: American Petroleum Institute, 2000
[12] Morison J R., O' Brien, M P.Johnson, J w..Schaaf, S.A. The Force Exerted by surface waves on piles. Petroleum Transaction. Vol.(189),1950, 149-157.

[13] S.E. Abdel Raheem, Elsayed M. A. Abdel Aal., "Nonlinear Analysis of Offshore Structures under Wave Loadings",15th WCEE 2428th SEPT 2012 Lisbon - Portugal Vol 1, 1-64, 2009.

[14] ABS, Guide for the Fatigue Assessment of Offshore Structure, American Bureau of Shipping, ABS Plaza,16855 Northchase Drive, Houston, TX 77060 USA, 2010.

[15] Kuang, J.G., A.B. Potvin, R.D. Leick and J.L. Kellick, 1977. Stress Concentration in Tubular Joints. Society of Petroleum Engineers Journal.

[16] R G Harwood , E P Shuttleworth "Grouted and mechanical strengthening and repair of tubular steel offshore structure",1988 Techword Services publishing, London.

[17] Lesani M. , Bahaari M.R. , Shokrieh M.M.," FRP wrapping for the rehabilitation of Circular Hollow Section (CHS) tubular steel connections", Thin-Walled Structures 90 (2015) 216-234.

[18] Samindi M.K. Samarakoon, R.M. Chandima Ratnayake. "Strengthening, modification and repair techniques prioritization for structural integrity control of ageing offshore structures". Reliability Engineering and System Safety 135 (2015)15-26.

[19] Gandhi, P., G., Raghava and D.S. Ramachandra Murthy, 2000. 'Fatigue Design of Offshore ring-stiffened welded steel tubular joints'. Journal of Structural Engineering, 126(7): 809-815.

[20] Graff, W.J., 1981. Introduction to Offshore Structures, Huston, Gulf Publishing. 